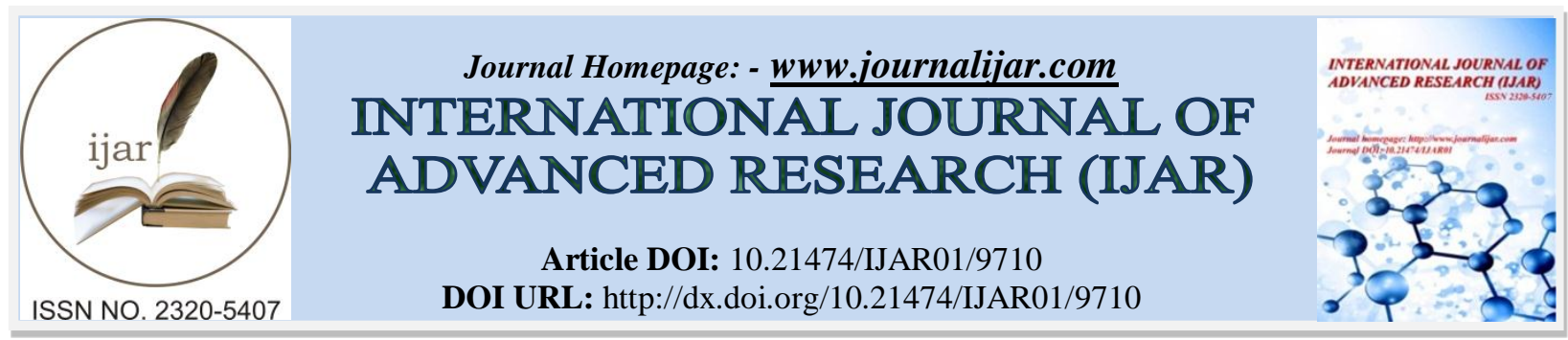

RESEARCH ARTICLE

\title{
A RETROSPECTIVE STUDY: HEARING IMPAIRMENT AND CONTRIBUTING FACTORS AMONG MANUFACTURING FACTORY WORKERS.
}

\author{
Adi Nurcahyadi, Kohar Sulistyadi and Soehatman Ramli.
}

Post Graduate School, Sahid University Jakarta, Indonesia.

\section{Manuscript Info}

Manuscript History

Received: 08 July 2019

Final Accepted: 10 August 2019

Published: September 2019

Key words:-

Hearing impairment, Manufacturing factory, Noise.

\begin{abstract}
Noise is an important occupational health hazard, with a high prevalence in the manufacturing industry. Expose to excessive noise can pose a risk to human health. Most commonly and of greatest interest, exposure to excessive noise may result in permanent damage to hearing. The aim of this study is to evaluate the determining factors of hearing impairment in manufacturing factory workers. Unmatched case control study was carried out among manufacturing factory workers at "XYZ" Company Qatar. Respondents consisted of 19 cases that were diagnosed from 2013 to 2018 with 176 controls from the same work place. Multivariate analysis was used to determine the association between hearing impairment and the contributing risks being studied. The results of partial logistic regression analysis showed aging $(\mathrm{p}<0.05)$, noise dose exposure $(\mathrm{p}<0.05)$ and infrequent use of HPD $(\mathrm{p}<0.05)$ associated to hearing impairment incident significantly. Service duration $(p>0.05)$, hypercholesterolemia ( $p>0.05)$, smoking $(p>0.05)$, diabetes $(p>0.05)$, and hypertension $(p>0.05)$ were not associated to the hearing impairment. Odd Ratio of noise dose exposure to hearing impairment $\operatorname{Exp}(\mathrm{B}) 11.8$ (95\% CI: 2.498-56.043), infrequent use of HPD $\operatorname{Exp}(B) 7.3$ (95\% CI: 2.366-22.585), and aging $\operatorname{Exp(B)}$ 1.121 (95\% CI: $1.023-1.228)$. In this study the author concludes that the noise dose exposure was strongest predictor to hearing impairment rather than infrequent use of HPD and aging factor.
\end{abstract}

Copy Right, IJAR, 2019,. All rights reserved.

\section{Introduction:-}

According to the U.S. Bureau of Labor Statistics, occupational hearing impairment is the most commonly recorded occupational illness in manufacturing (17,700 cases out of 59,100 cases), accounting for 1 in 9 recordable illnesses. More than $72 \%$ of these occur among workers in manufacturing ${ }^{(1)}$. Approximately 22 million U.S. workers are exposed to hazardous occupational noise ${ }^{(2)}$. CDC compared the prevalence of hearing impairment within nine U.S. industry sectors using 1,413,789 noise-exposed worker audiograms from CDC's National Institute for Occupational Safety and Health (NIOSH) Occupational Hearing impairment Surveillance Project ${ }^{(3)}$. CDC estimated the prevalence at six hearing impairment levels, measured in the better ear, and the impact on quality of life expressed as annual disability-adjusted life years (DALYs), as defined by the 2013 Global Burden of Disease (GBD) Study ${ }^{(4)}$. The mining sector had the highest prevalence of workers with any hearing impairment, and with moderate or worse impairment, followed by the construction and manufacturing sectors. The NIOSH-1997 model estimates that the risk

Corresponding Author:-Adi Nurcahyadi.

Address: Post Graduate School, Sahid University Jakarta, Indonesia. 
of suffering hearing impairment was 4.3 (95\% CI 1.3-9.4) when person exposed to daily noise at $85 \mathrm{~dB}(\mathrm{~A})$, having worked for more than 10 years and aged 40 years old ${ }^{(5)}$.

Among all industries, 13\% of noise-exposed workers had hearing impairment and 2\% had moderate or worse impairment. Workers with hearing impairment were represented in all industry sectors, with sharply decreasing numbers of workers with higher levels of impairment. The mining sector had the highest prevalence of workers with any impairment $(17 \%)$ and with moderate or worse impairment $(3 \%)$, followed by the construction sector (any impairment $=16 \%$, moderate or worse impairment $=3 \%)$, and the manufacturing sector $(14 \%$ and $2 \%)$. The public safety sector, which includes police protection, fire protection (including wildland firefighters), corrections, and ambulance services, had the lowest prevalence of workers with any impairment $(7 \%)^{(6)}$.

The contributing factors of hearing impairment were categorized into occupational noise exposure, non-occupational noise exposure (such as free time noise exposure and firearm activities), individual susceptibility such as sociodemography (age, gender, and job title), smoking habit, medical problems (hypertension, diabetes mellitus, hyper cholesterolemia, and infections), ototoxic drugs, compliance to hearing protection device (HPD) usage ${ }^{(7)}$. Few studies have found that smoking habits, education levels, noisy entertainments, firearm activities, ototoxic drugs, medical problems, and HPD usage have contributed to hearing impairment ${ }^{(8)}{ }^{(9)}$.

Hearing impairment as a result of exposure to noise is one of the most frequent pathologies found in workers, and is influenced by a number of parameters, such as intensity of the noise, temporal and spectral patterns, duration of the exposure and susceptibility factors. Controlling these parameters may improve the individual response to noise and evolution of the damage. One of the factors influencing hearing susceptibility which has attracted growing interest in recent years is cigarette smoking, although the role of smoking in abetting the development of sensory neural hearing impairment is controversial, as recent literature shows. Some authors highlight that smokers have a greater risk of hearing impairment than non-smokers ${ }^{(10)}$, while others find no connection between the onset of sensory neural hearing impairment and cigarette smoking ${ }^{(11)}$. Nomura in a reviewed referring to the period 1966-2003, mentions nine studies which report a positive association between smoking and hearing impairment, and six studies which reach completely opposite conclusions. The author, however, concludes by supporting the thesis of a positive association between smoking and hearing impairment ${ }^{(12)}$.

Several studies have demonstrated a relationship between hyperlipidemia and hearing disturbance ${ }^{(13)(14)}$. Although, some studies have reported that levels of triglycerides and cholesterol were not consistently related to hearing disturbance, these studies nevertheless attested to the relevance of low-versus high-density lipoprotein ${ }^{(15)}(16)$. The association of hearing impairment with Diabetes Mellitus (DM) however, is still controversial. Several studies have shown no or little association between DM and hearing impairment ${ }^{(17)(18)}$ and a cohort study reported that DM was associated with the development of bilateral hearing impairment ${ }^{(19)}$.

Hearing impairment is one of the most prevalent chronic conditions in adults worldwide ${ }^{(20)}$ and it is classified as conductive, sensorineural or mixed in type. Conductive hearing impairment has readily identifiable causes and is easily amenable to treatment but sensorineural hearing impairment has more grievous consequences on the individual. Good hearing function is particularly required for adults in the working population who are exposed to noise and other challenging listening situations at work. Because hearing impairment due to noise is irreversible, early detection and intervention is critical to prevention of this condition. Ensure baseline audiograms are obtained for new hires and or employees newly identified as working within a noise-laden environment. A 10-dB confirmed threshold shift from baseline in pure-tone average at 2000, 3000, and $4000 \mathrm{~Hz}$ (OSHA standard threshold shift or STS), while not necessarily resulting in significant impairment, is an important early indicator of permanent hearing impairment ${ }^{(21)}$.

The "XYZ" company is one of manufacturing industries located in Qatar. Noise level measurements were undertaken in December 2018 by Environment department of "XYZ" Company in the selected areas, using a calibrated direct reading instrument, "EXTECH sound level meter - 407736", to identify work areas where employees exposures may be above hazardous levels and where a deep/thorough exposure monitoring may be required. A number of representative readings were undertaken in different points surrounding area / vessel which might contribute to environmental noise. The meter was set to the " $\mathrm{A}$ " scale (which corresponds most closely to the response of the human ear), and slow response mode, for environment noise. The maximum noise level measured in the plant was $113.5 \mathrm{~dB}$ and the minimum reading was $79.4 \mathrm{~dB}$. As part of their hearing conservation program, 
periodic audiometric testing was conducted to 302 employees who exposed to noise environment annually by the certified and qualified technician at occupational health clinic of "XYZ" Company. The latest report in 2018 found some cases of hearing impairment $7.6 \%$ among the workers.

Based on the description above, the author is interested in researching the contributing factors of hearing impairment in manufacturing factory at "XYZ" Company Qatar. The aim of the study is to evaluate the contributing factors of hearing impairment in manufacturing industry.

\section{Methods:-}

Type of the research used quantitative observational analytics with retrospective case control approach. The manufacturing factory was selected on the basis of incidence of hearing impairment and to assist the factory in optimizing their hearing conservation program. The dependent variable was hearing impairment and the independent variables were aging, service duration, hearing protection device use, smoking status, medical history of hypertension, hypercholesterolemia, and diabetes mellitus.

The research was conducted at Manufacturing Factory in Qatar from March 2019 to July 2019. Nineteen workers with sensorineural hearing impairment were studied retrospectively. The inclusion criteria consisted of workers working in the noise area, consisted of workers aged 30-60 years with a mean loss of more than $25 \mathrm{dBHL}$ averages between the four frequencies $0,5 \mathrm{kHz}, 1 \mathrm{kHz}, 2 \mathrm{kHz}$ and $4 \mathrm{kHz}{ }^{(22)}$, free of ear infections or trauma or surgery, have been working for more than 5 years, no previous occupational history of noisy jobs and agree to participate. Exclusion criteria comprised a history suggestive of a congenital hearing impairment maternal rubella, kernicterus, meningitis, syphilis, head injury or ototoxic drugs. Other exclusion criteria were if they had abnormal syphilis serology, auto anti bodies or thyroid function tests (two subjects) although there is no consistent evidence that hypothyroidism is associated with hearing impairment this was excluded as a possible confounding variable. The control group $(\mathrm{N}=176)$ was recruited from workers who have been working in same company and willingness to participate.

The data consist of primary data and secondary data. Primary data obtained through questionnaire and interview while secondary data obtained through medical records. Throughout the survey, the methods used included a Pure Tone Audiometric (PTA) test, a questionnaire, a personal dosimeter report, recent fasting blood sugar report, blood pressure report and cholesterol results. The audiometry machine was approved and calibrated conforming to the standard requirement by the regulation body in the country. The audiometric tests were conducted in the factory clinic. The audiometric tests were conducted by trained qualified technician after otoscopy examination by doctor. Hearing thresholds were measured in sound-treated booths by pure-tone air $(0.5,1,2,3,4,6,8 \mathrm{kHz})$ and bone conduction $(0.5,2,4 \mathrm{kHz})$ audiometry using a modified Hughson-Westlake procedure according to the guidelines of the American Speech-Language-Hearing Association. ${ }^{(23)}$ Masking was used as necessary. The presence of hearing impairment was defined as a pure-tone average (PTA) of thresholds at $0.5,1,2$, and $4 \mathrm{kHz}$ greater than $25 \mathrm{~dB}$ hearing level in either ear. A second definition of PTA greater than $25 \mathrm{~dB}$ hearing level in the better ear was also used to capture bilateral hearing impairment. This 4-frequency average has long been used as a measure of hearing impairment in epidemiologic studies ${ }^{(24)}$. The annual audiogram was screened to determine hearing impairment by looking into the latest audiogram results, and repeated PTA tests were done for confirmation. The PTA tests were performed after 14 hours free from end of work shifts. The self-administered questionnaire sessions were conducted in the factory's clinic with the presence of the investigator.

The report of personal dosimeter at same work places was conducted in 2018 by registered industrial hygienist in the company. Cirrus CR:110A dosimeter was used with standard ANSI S1.25 and was calibrated frequently. The list of daily personal noise dose in different job titles and work locations was tabulated. These findings were used to determine daily noise dose exposure subjects by questioning their job title and work location since joining this factory. Based on the noise exposure recommendations from NIOSH, the $100 \%$ daily noise dose means subjects who work in 8 hours per day equivalent to $90 \mathrm{~dB}(\mathrm{~A})$, whereas subjects who work in 12 hour shifts per day was adjusted equivalent to $87 \mathrm{~dB}(\mathrm{~A})$ (5). Meanwhile OSHA recommends the daily noise dose exposure $85 \mathrm{~dB}$ (A) TWA 8 hours per day ${ }^{(25)}$.

Fasting blood sugar, cholesterol and blood pressure results were based on existing medical records and were reanalyzed by an accredited laboratory in early 2019 as part of their healthy life style program. Diabetes mellitus was defined as a fasting plasma glucose level of $126 \mathrm{mg} / \mathrm{dL}$ or greater (to convert to millimoles per liter, multiply by 
0.0555), 2-hour postload plasma glucose level of $200 \mathrm{mg} / \mathrm{dL}$ or greater, a hemoglobin $\mathrm{A}_{1 \mathrm{c}}$ of $6.5 \%$ or greater, selfreport of doctor-diagnosed diabetes (excluding gestational diabetes), or use of anti-hyperglycemic medications ${ }^{(26)}$.

Dyslipidemia was diagnosed according to National Cholesterol Education Program ATP III criteria ${ }^{(27)}$ and defined as TC >200mg/dL, LDL-C > 160mg/dL, HDL-C 150mg/dL. Hypertension was defined as a systolic blood pressure of $140 \mathrm{~mm} \mathrm{Hg}$ or greater, diastolic blood pressure of $90 \mathrm{~mm} \mathrm{Hg}$ or greater, or receipt of antihypertensive medication. ${ }^{(28)}$ (29) The items surveyed included the following: 1) socio-demographic data (age, and job title), 2) occupational noise exposure (daily noise dose and service duration), 3) Hearing Protection Device/HPD (Frequency of usage), 5) smoking status, 6) medical condition (hypertension, Diabetes Mellitus, and hypercholesterolemia).

Data were statistically analyzed using SPSS version 25.0 software package. Partial logistic regression analysis was used to determine the association between independent variables and dependent variable. The significance of the result was set at $\mathrm{p}<0.05$. Logistic regression analysis was performed to determine odd ratio and $95 \%$ confidence interval (CI). Descriptive analysis also used to analyze data by frequency, mean and distribution of the respondents.

\section{Results:-}

Table 1.1 showed, Total participant were 195, consisting $19(9.7 \%)$ cases and $176(90.3 \%)$ controls. Univariate analysis results found the age of case group were a little over 3.8 years older on average than the age of control group. The cases had an average 47.1 years and the controls had an average of 43.3 years. The age of case group had a standard deviation of 5.7 years whereas the controls age data had a standard deviation 6.1. The control data having a higher standard deviation tells us that the age of control group data was more spread out or dispersed than the data from the case. The jobs of the respondent were mostly as an operator. The respondents from the case worked as an operator $89.5 \%$ and $10.5 \%$ worked as a technician.

The mean daily noise exposure of cases data was $87.7 \mathrm{~dB}(\mathrm{~A})$ whereas the mean control data was $85.0 \mathrm{dBA}$ It means the average of the noise exposure of the case group was higher $2.7 \mathrm{~dB}(\mathrm{~A})$ exposed to the noise than the control group. The prevalence of case group with high cholesterol was $31 \% .6$ and the control group was $29.0 \%$. From the descriptive analysis also shown the case group was mostly nonsmokers $94.7 \%$, as well as the control group was $87.5 \%$. The DM prevalence was $89.5 \%$ in the case group and $89.8 \%$ was in the control group. It showed the prevalence of DM between case and control was almost similar. The participant who had history of hypertension was $94.7 \%$ in case group and $98.3 \%$ in control group. Infrequent hearing protection device (HPD) usage was $68.4 \%$ among case group and $29.0 \%$ among the control group. The result demonstrated that infrequent use of HPD in case group was higher than in control group.

Tabel 1.1:-Demographic and hearing impairment risk factors, by subject group

\begin{tabular}{|l|l|l|}
\hline Characteristic & $\begin{array}{l}\text { Case } \\
(\mathbf{N = 1 9 )}\end{array}$ & $\begin{array}{l}\text { Control } \\
(\mathbf{N = 1 7 6})\end{array}$ \\
\hline Age, yrs (mean \pm SD) & $47.1 \pm 5.7$ & $43.3 \pm 6.1$ \\
\hline Service duration, yrs (mean \pm SD) & $14.9 \pm 4.9$ & $14.1 \pm 4.8$ \\
\hline Job title & & \\
\hline Operator (\%) & 89.5 & 88.6 \\
\hline Technician (\%) & 10.5 & 11.4 \\
\hline Cholesterol & & \\
\hline Normal (\%) & 68.4 & 71.0 \\
\hline High (\%) & 31.6 & 29.0 \\
\hline Smoking & & \\
\hline Nonsmoker (\%) & 94.7 & 87.5 \\
\hline Smoker (\%) & 5.3 & 12.5 \\
\hline Diabetes mellitus & & \\
\hline Non diabetes mellitus (\%) & 89.5 & 89.8 \\
\hline Diabetes mellitus (\%) & 10.5 & 10.2 \\
\hline Hypertension & & \\
\hline Non hypertension (\%) & 94.7 & 98.3 \\
\hline Hypertension (\%) & 5.3 & 7.39 \\
\hline Noise dose exposure, dBA (mean \pm SD) & $87.7 \pm 4.2$ & $85.0 \pm 4.0$ \\
\hline HPD & & \\
\hline & & \\
\hline
\end{tabular}




\begin{tabular}{|l|l|l|}
\hline Always use HPD (\%) & 31.6 & 71.0 \\
\hline Infrequent use of HPD (\%) & 68.4 & 29.0 \\
\hline
\end{tabular}

Table 1.2 showed logistic regression enter method analysis result, age $(p<0.05)$, noise dose exposure $(p<0.05)$ and not all the times used HPD $(p<0.05)$ associated to hearing impairment incident. Factors Service duration ( $>0.05)$, hypercholesterolemia $(p>0.05)$, smoking $(p>0.05)$, diabetes $(p>0.05)$, and hypertension $(p>0.05)$ were not associated to the hearing impairment.

Table 1.2:-Partial Logistic Regression Analysis

\begin{tabular}{|l|r|r|r|r|r|l|}
\hline Variable & \multicolumn{1}{|c|}{ B } & \multicolumn{1}{|c|}{ Sig. } & \multirow{2}{*}{$\operatorname{Exp}(\mathbf{B})$} & \multicolumn{2}{|c|}{$\mathbf{9 5 \%}$ C.I.for EXP(B) } & \multirow{2}{*}{ Remarks } \\
\cline { 5 - 6 } & & & & \multicolumn{1}{c|}{ Lower } & \multicolumn{1}{c|}{ Upper } & \\
\hline Aging & 1.536 & .049 & 4.644 & 1.005 & 21.469 & Significant \\
\hline Service duration & -.187 & .830 & .829 & .151 & 4.567 & Insignificant \\
\hline Hypercholesterolemia & .453 & .610 & 1.573 & .276 & 8.956 & Insignificant \\
\hline Smoking & -1.244 & .302 & .288 & .027 & 3.063 & Insignificant \\
\hline Diabetes Mellitus & -.031 & .973 & .969 & .158 & 5.939 & Insignificant \\
\hline Hypertension & -1.744 & .161 & .175 & .015 & 2.003 & Insignificant \\
\hline Noise dose exposure & 2.793 & .001 & 16.326 & 3.257 & 81.847 & Significant \\
\hline Infrequent use of HPD & 2.137 & .001 & 8.476 & 2.451 & 29.314 & Significant \\
\hline Constant & -6.298 & .000 & .002 & & & \\
\hline
\end{tabular}

From table 1.3, Odd Ratio of Noise dose exposure to hearing impairment $\operatorname{Exp}(\mathrm{B}) 11.8$ (95\% CI: 2.498-56.043), infrequent use of HPD $\operatorname{Exp}(B) 7.3$ (95\% CI: 2.366-22.585), and aging $\operatorname{Exp}(\mathrm{B}) 1.121$ (95\% CI: 1.023-1.228). Based on the result above, we can conclude that the noise dose exposure was highest factor associated to hearing impairment rather than wearing HPD and employee age.

Table 1.3:-Logistic Regression Analysis

\begin{tabular}{|l|r|r|r|r|r|r|r|r|}
\hline Variable & \multicolumn{1}{|c|}{ B } & S.E. & Wald & df & \multicolumn{1}{|l|}{ Sig. } & Exp(B) & \multicolumn{2}{|c|}{ 95\% C.I.for EXP(B) } \\
\cline { 5 - 9 } & 2.471 & .794 & 9.696 & 1 & .002 & 11.833 & 2.498 & 56.043 \\
\hline $\begin{array}{l}\text { Noise dose } \\
\text { exposure }\end{array}$ & 1.989 & .575 & 11.949 & 1 & .001 & 7.311 & 2.366 & 22.585 \\
$\begin{array}{l}\text { Infrequent use } \\
\text { of HPD }\end{array}$ & .114 & .047 & 5.966 & 1 & .015 & 1.121 & 1.023 & 1.228 \\
\hline Aging & -10.115 & 2.419 & 17.483 & 1 & .000 & .000 & & \\
\hline Constant & & &
\end{tabular}

Table 1.4 showed, prediction analysis with Nagelkerke $\mathrm{R}^{2}: 0.335$. Noise dose exposure, infrequent use of HPD and age predicted influence of hearing impairment $33.5 \%$. 66.5\% influenced by other factors which not describe above.

Table 1.4:-Logistic Regression Analysis

\begin{tabular}{|l|c|c|c|}
\hline Step & -2 Log likelihood & Cox \& Snell R Square & Nagelkerke R Square \\
\hline 1 & $90.961^{\mathrm{a}}$ & .158 & .335 \\
\hline \multicolumn{2}{|l|}{ a. Estimation terminated at iteration number 7 because parameter estimates changed by less than .001.} \\
\hline
\end{tabular}

\section{Discussion:-}

The research design was case control which hearing impairment sample as the case and the control was other workers who worked at same exposure within the company. The dependent variable was hearing impairment and the independent variables were aging, service duration, noise dose exposure, HPD usage, smoking status and medical condition (hypertension, diabetes mellitus, and hypercholesterolemia). The case control study design was used in this study which suitable for the rare disease related to hearing on the industrial workers and chronic medical problem in workers exposed to noise. The advantage of this research design is less costly and shorter in duration compared to prospective cohort study. The limitation of this research is study population, which only depends on respondents who were still working. Case control research mainly in this study relying on medical records at company clinic. The accuracy of this medical data depends on the registrar, medical devices, data completeness, and 
possibilities lost medical data. Medical check-up data (pre-employment and periodic medical check-up) did not exist or incomplete, especially data before 2015 .

The 19 case of hearing impairment in the manufacturing factory at "XYZ" Company is associated with noise dose exposure, infrequent use of HPD and aging factor. These variables predicted influence of hearing impairment $33.5 \%$. Meanwhile $66.5 \%$ influenced by other factors which not described in this study. Noise dose exposure OR 11.833 (95\% CI: 2.366-22.585) factor was the strongest contribution of hearing impairment in this study. This finding are consistent with report of Rachiotis ${ }^{(30)}$ findings indicate that electro production workers were occupationally exposed to high levels of noise, and present high rates of noise-induced hearing impairment (NIHL). Hearing impairment due to continuous or intermittent noise exposure increases most rapidly during the first 10 to 15 years of exposure, and the rate of hearing impairment then decelerates as the hearing threshold increases. This is in contrast to age-related loss, which accelerates over time ${ }^{(31)}$. This result was in line with many studies result which noise exposure is one of hearing impairment contributing factors ${ }^{(32)}$. There are a number of other causes of sensorineural hearing impairment besides occupational noise. Of primary concern is non-occupational noise exposure from a variety of sources, especially recreational noise, such as loud music, weapons firing, motor sports, etc. Other causes include a wide variety of genetic disorders, infectious diseases (eg, labyrinthitis, measles, mumps, syphilis), pharmacologic agents (eg, aminoglycosides, diuretics, salicylates, antineoplastic agents), head injury, therapeutic radiation exposure, neurologic disorders (eg, multiple sclerosis), cerebral vascular disorders, immune disorders, bone (eg, Paget disease), central nervous system neoplasms, and Menière's disease. A medical history can help in determining whether any of these conditions could contribute to an individual's hearing impairment ${ }^{(33)}$.

Aging is well-known as contributing factor of hearing impairment; the result of our study was consistent in this regard as shown OR 1.121 (CI 95\%, 1.023-1.228). The average age of case group was 47.1 years old and the average age of control group was 43.3 years old. So we can conclude the risk of hearing impairment increasing by aging factor. Davis found that in under 45 years old there was not much hearing impairment and mild hearing impairment increases to 1 in 3 of the population for 55-64 years old ${ }^{(34)}$. Other study also reported that increasing age was associated with hearing impairment across all frequency definitions of PTA but with greater hearing impairment changes seen at the higher frequencies ${ }^{(35)}$.

As per result of regression analysis showed a positive association of hearing impairment and infrequent use of HPD with OR 7.3 (95\% CI: 2.366-22.585) in this study. Only 31.6\% of the employees exposed to noise always wore hearing protection device at work, meaning that $68.4 \%$ of the case group state was not wearing hearing protection device all the time. A study by Starck et al. found that paper and pulp factory workers who wore HPD for 50\% of the required duration showed more hearing loss ${ }^{(36)}$. Bauer et al, also found a positive association between of the usage of HPDs and hearing impairment by analyzing a very large population of workers exposed to occupational noise ${ }^{(37)}$. A study to understand factors influencing the use of hearing protection identified that interpersonal support, barriers, and situational influences as statistically significant predictors of low use of hearing protection device. ${ }^{(38)}$ Real world attenuation provided by hearing protective devices may vary widely between individuals. The noise-reduction rating of hearing protective devices used by a working population is expected to be less than the laboratory-derived rating ${ }^{(39)}(40)$. Hearing protective devices should provide adequate attenuation to reduce noise exposure at the eardrum to less than $85 \mathrm{~dB}$ time-weighted average. In addition, technology is now available, which can provide an individualized attenuation rating for hearing protective devices and continuous monitoring of noise at the eardrum ${ }^{(41)(42)}$.

\section{Conclusion:-}

This study has shown consistent evidence to indicate that aging, infrequent use of HPD and noise dose exposures were contributing factors in hearing impairment. The strongest contributor of hearing impairment was noise dose exposure. Meanwhile service duration, hypercholesterolemia, hypertension, diabetes mellitus and smoking were not associated with hearing impairment.

Hearing impairment prevention, and early detection and intervention to avoid additional hearing impairment, are critical to preserve worker quality of life. Elimination of the hazard is the ideal standard. For example, when plant machinery is replaced, the noise output should be considered in the contract specifications. With machinery and equipment that cannot be submitted the maintenance schedule should be considered because poorly maintained equipment tends to be noisy. It is vital that all workers who exposed to the noise are educated adequately to encourage them to wear hearing protective device. Occupational hearing impairment is preventable through a 
hierarchy of controls, which prioritize the use of engineering controls over administrative controls and personal protective equipment. NIOSH recommends re-survey for the noise at work every two years ${ }^{(5)}$, while OSHA only requires re-survey when conditions change for the worse ${ }^{(25)}$. By conducting regular surveys using similar protocols, trends and comparisons can be drawn. These have proven to be useful communication tools to assist in driving hearing loss prevention program decisions. ${ }^{(43)}$. Further research needs to be done to analyze others factors may contribute to hearing impairment.

\section{Competing Interests}

Authors have declared that no competing interests exist. These products used for this research are commonly and predominantly use product in our area of research and country. There is absolutely no conflict of interest between the authors and producers of the products because we do not intend to use these products as an avenue for any litigation but for the advancement of knowledge. Also, the research was not funded by the producing company rather it was funded by personal efforts of the authors.

\section{References:-}

1. NIOSH. Centers for Disease Control and prevention. CDC. [Online] 2010. [Cited: June 3, 2019.] https://www.cdc.gov/niosh/docs/2010-136/pdfs/2010-136.pdf.

2. Tak S, Davis RR, Calvert GM. s.l. Exposure to hazardous workplace noise and use of hearing protection devices among US workers--NHANES, 1999-2004. American Journal of Industrial Medicine, 2009, American Journal of Industrial Medicine, pp. 358-71.

3. Masterson EA, Tak S, Themann CL, et al. Prevalence of hearing loss in the United States by Iindustry. 2013, Am J Ind Med, pp. 670-81.

4. Collaborators, Global Burden of Disesase Study Global, regional, and national incidence, prevalence, and years lived with disability for 301 acute and chronic diseases and injuries in 188 countries, 2015, The Lancet, pp. 743800.

5. NISOH. Criteria for a recommended standard: Occupational Noise Exposure. (NIOSH), National Instiute for Occupational Safety and Health. 126, Cincinnati: DHHS (NIOSH) publication, 1998, Vol. 98.

6. Masterson EA, Bushnell PT, Themann CL, Morata TC. 15, s.l.: Hearing Impairment among Noise-Exposed Workers - United States, 2003-2012. CDC, April 22, 2016, Vol. 65, pp. 389-394.

7. Lee JS, Choi HG, Jang JH, Sim S, Hong SK, Lee HJ, Park B, Kim HJ. s.l. Analysis of Predisposing Factors for Hearing Loss in Adults. J Korean Med Sci, 2015, Vol. 8, pp. 1175-1182.

8. Arezes PM, Miguel AS. Hearing protection use in industry: The role of risk perception.. 2005, Safety Science, Vol. 43, pp. 253-267.

9. Stanbury M, Rafferty AP, Rosenman K. 2008. Prevalence of Hearing. J Occup Environ Med, Vol. 50, pp. $72-$ 79 .

10. Starck, J., Toppila, E. and Pyykko, I. 3, s.l. Smoking as a risk factor in sensory neural hearing loss among workers exposed to occupational noise.: Acta Otolaryngology, 1999, Vol. 119.

11. Sharabi, Y., Reshef-Haran, I., Burstein, M. and Eldav, A. Cigarette smoking and hearing loss: Lessons from the young adult periodic examinations in Israel. Israel Medical Association Journal, 2002, Vol. 4.

12. Nomura, K., Nakao, M. and Morimoto, T. Effect of smoking on hearing loss Quality assessment and metaanalysis.: Preventive Medicine, 2005, Vol. 40.

13. Thakur JS, Mohindroo NK, Vasanthalakshmi MS, Kashyap N, Azad RK, Sharma DR. Auditory brainstem evoked responses in hyperlipidaemia: effect of various lipid fractions on auditory function. J Laryngol Otol, 2012, Vol. 126.

14. Karlidağ T, Açik Y, Kaygusuz I, Yalçin S, Güngör MY, Demirbağ E. The effect of hyperlipidemia on hearing function. 112-116, s.l. : Kulak Burun Bogaz Ihtis Der, 2002, Vol. 9.

15. Gates GA, Cobb JL, D'Agostino RB, Wolf PA. The relation of hearing in the elderly to the presence of cardiovascular disease and cardiovascular risk factors. 1993, Arch Otolaryngol Head Neck Surg, Vol. 119, pp. 156-161.

16. Friedrich G, Pilger E. Lipoproteins in cochleovestibular disorders (author's transl). 1981, Arch Otorhinolaryngol, Vol. 232, pp. 101-105.

17. SG, Harner. Hearing in adult-onset diabetes mellitus, 1981, Otolaryngol Head Neck Surg, Vol. 89, pp. 322-327.

18. Hodgson MJ, Talbott E, Helmkamp JC et al. Diabetes, noise exposure, and hearing loss. 1987, J Occup Med, Vol. 29, pp. 576-579.

19. Min-Beom Kim, Yiyi Zhang, Yoosoo Chang, Seungho Ryu, Yuni Choi, Min-Jung Kwon, Il Joon Moon, Jennifer A Deal, Frank R Lin, Eliseo Guallar, Eun Chul Chung, Sung Hwa Hong, Jae Ho Ban, Hocheol Shin, 
Juhee Cho. Diabetes mellitus and the incidence of hearing loss: a cohort study. 2017, International Journal of Epidemiology, Vol. 46, pp. 717-726.

20. Smith PA, Davis AC, Pronk M, Stephens D, krmaer SE, Thodi C, et al. Adult Hearing Screening: What comes next? 2009, Int J Audiol, pp. 684-91.

21. RA, Dobie. Audiometric threshold shift definitions: simulations and suggestions. 2005, Ear Hearing, Vol. 26, pp. 62-77.

22. N.S.Jones, A. Davis. Nottingham. A propsepctive case- controlled study of patient's presneting with idiopathic sensorineural hearing loss to examine the relationship between hyperlipidemia and sensorineuarl hearing loss. UK : Clin. Otolaryngeal, 1999, Vol. 24.

23. Association, American Speech-Language-Hearing. Guidelines for manual pure tone audiometry. 1978, ASHA, Vol. 20, pp. 287-301.

24. AC. Davis. The prevalence of hearing impairment and reported hearing disability among adults in Great Britain. 1989, Int J Epidemiol, Vol. 18, pp. 911-917.

25. OSHA, Occupational Safety and Health Administration. [Online] 2002. [Cited: July 16, 2019.] https://www.osha.gov/Publications/osha3074.pdf.

26. Schneiderman N, Llabre M, Cowie CC, et al. Prevalence of diabetes among Hispanics/Latinos from diverse backgrounds: the Hispanic Community Health Study/Study of Latinos (HCHS/SOL). Diabetes Care, 2014 , Vol. 37, pp. 2233-2239.

27. Expert Panel on Detection, Evaluation and Treatment of High Blood Cholesterol inAdults. Report, Executive summary of the third. 2486, s.l. : JAMA, 2001, Vol. 285.

28. De Moraes Marchiori LL, de Almeida Rego FE, Matsuo T. Hypertension as a factor associated with hearing loss. Sao Paulo, Bras J Otorhinolaringol, 2006, Vol. 72.

29. Daviglus ML, Talavera GA, Avilés-Santa ML, et al. Prevalence of major cardiovascular risk factors and cardiovascular diseases among Hispanic/Latino individuals of diverse backgrounds in the United States. 2012, JAMA, Vol. 308, pp. 642-649.

30. Rachiotis G, Alexopoulos C, Drivas S. Occupational exposure to noise, and hearing function among electro production workers. Epub, 2006, Auris Nasus Larynx, Vol. 33, pp. 381-385.

31. Durch JS, Joellenbeck LM, Humes LE, eds. Noise and Military Service: Implications for Hearing Loss and Tinnitus. Washington, DC : National Academies Press, 2005.

32. Rachiotis G1, Alexopoulos C, Drivas S. Occupational exposure to noise, and hearing function among electro production workers. Dec 2006, Auris Nasus Larynx, Vol. 33.

33. H, Arts. Sensorineural hearing loss in adults. In: Otolaryngology. Philadelpia: Mosby Elsevier, 2010. Vol. 5.

34. A Davis, KA Davis. Epidemiology of aging and hearing loss related to other chronic illnesses. 2010, Hearing Care for Adults.

35. Frank R. Lin, Roland Thorpe, Sandra Gordon-Salant, Luigi Ferrucci. Hearing Loss Prevalence and Risk Factors Among Older Adults in the United States. 2011, Gerontology, Vol. 66A, pp. 582-590.

36. Claussen CF, Kirtane MV,. Starck J, Pyykko I, Pekkarinen. Effect of smoking on sensory neural hearing loss.. Amssterdam : Elsevier Publishing, 1988, Vertigo, nausea, tinnitus and hypoacusia, pp. 347-350.

37. Bauer P, Ko rpert K, Neuberger M, Raber A, Schwertz F. Risk factors for hearing loss at different frequencies in a population of 47.388 noise-exposed workers. 1999, J Acoust Soc Am, Vol. 90, pp. 3086-3098.

38. McCullagh, Marjorie, Lusk, Sally L. and Ronis, David L. Factors Influencing Use of Hearing Protection Among Farmers: A Test of the Pender Health Promotion Model. 2002, Nursing research, Vol. 51, pp. 33-39.

39. Lusk SL, Kerr MJ, Kauffman SA. Use of hearing protection and perceptions of noise exposure and hearing loss among construction workers. 1998, Am Ind Hyg Assoc J, Vol. 59, pp. 466-470.

40. Berger EH, Franks JR, Behar A, et al. Development of a new standard laboratory protocol for estimating the field attenuation of hearing protection devices. Part III. The validity of using subject-fit data. 1998, J Acoust Soc Am, Vol. 103, pp. 665-672.

41. LD, Hager. Fit-testing hearing protectors: an idea whose time has come. 2011, Noise Health, Vol. 13, pp. 147151 .

42. TY, Schulz. Individual fit-testing of earplugs: a review of uses. 2011, Noise Health, Vol. 13, pp. $152-162$.

43. Hager L, Johnson C. A Strategy for Assesing and Managing Occupational Exposure. 4. s.l.: American Industrial Hygiene Association, 2015. pp. 197-203. 978-1935082460. 